\title{
Globalización en la postmodernidad: críticas y contribuciones para la enfermería
}

\section{Globalization in postmodernity: criticism and contributions for nursing \\ Globalização na pós-modernidade: críticas e contributos para a enfermagem}

\author{
Antonio Jorge Silva Correa Júnior ${ }^{1}$; Mary Elizabeth de Santana ${ }^{2}$; \\ Gesiany Miranda Farias ${ }^{3}$; Edson Costa Noronha ${ }^{4}$ \\ ${ }^{1}$ Enfermeiro. Mestrando em Enfermagem pela Universidade Federal do Pará em "Políticas de Saúde no \\ Cuidado de Enfermagem Amazônico. Correo electrónico: juniorjorge_94@hotmail.com \\ ${ }^{2}$ Enfermeira. Pós-doutora em Enfermagem pela Escola de Enfermagem de Ribeirão Preto da Universidade de \\ São Paulo. Correo electrónico: marybete@ufpa.br \\ ${ }^{3}$ Enfermeira. Mestranda em Enfermagem pela Universidade Federal do Pará em "Políticas de Saúde no \\ Cuidado de Enfermagem Amazônico. Correo electrónico: gesiany.farias@hotmail.com \\ ${ }_{4}^{4}$ Filósofo. Professor efetivo da Universidade Federal do Pará. Correo electrónico: noronhaufpa@gmail.com \\ Cómo este artículo en edición digital: Correa Júnior, A. J. S., Santana, M. E., Farias, G. M. \& Noronha, \\ E. C. (2019). Globalización en la postmodernidad: críticas y contribuciones para la enfermería. Cultura \\ de los Cuidados (Edición digital), 23(53). Recuperado de http://dx.doi.org/10.14198/cuid.2019.53.25 \\ Correspondencia: Antonio Jorge Silva Correa Júnior. Universidade Federal do Pará, Faculdade de \\ Enfermagem, Sala do Mestrado, Instituto de Ciências da Saúde. Cidade Universitária Professor José da \\ Silveira Netto no Campus Profissional III. Complexo da Saúde.- Rua Augusto Corrêa, Bairro do Guamá. \\ CEP: 66075110 - Belém, Pará, Brasil \\ Correo electrónico: juniorjorge_94@hotmail.com \\ Recibido: 11/11/2018; Aceptado: 28/02/2019
}

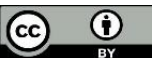

\section{ABSTRACT}

The target of this critical reflection was the approach of globalization, consumption and identity described by Zygmunt Bauman, establishing links with work, education and formation in nursing. The results and discussion were segmented into three axes. The first contemplates how globalization is associated with labor flexibilization, merchandization of citizenship, rights and health. The second axis reflects within the postmodern itinerary the education and formation of nurses, with emphasis for the concepts of permanent education / politics and the role of the teacher. The third axis consumes momentarily assertions, to approach the obstacles that globalized teaching lifts as "distance learning." In vain, would be to dissociate global postmodern phenomena from the conjuncture faced by the profession. It is corroborated for the establishment of a theoretical-socio-identity thinking since the nursing formation.

Keywords: Globalization, postmodernity, postmodern culture, nursing education, nursing baccalaureate, curriculum.

\section{RESUMO}

O alvo desta reflexão crítica foi a 
abordagem de globalização, consumo e identidade como descritos por Zygmunt Bauman, estabelecendo nexos com trabalho, educação e formação em enfermagem. Os resultados e discussão foram segmentados em três eixos. O primeiro contempla como a globalização está associada à flexibilização do trabalho, mercantilização da cidadania, direitos e saúde. O segundo eixo reflete dentro do itinerário pós-moderno a educação e formação de enfermeiros com destaque para os conceitos de educação permanente/política e o papel do professor. O terceiro eixo consuma momentaneamente as assertivas, ao abordar os obstáculos que o ensino globalizado ergue como a "formação à distância". Debalde seria dissociar fenômenos globais pós-modernos da conjuntura enfrentada pela profissão. Corrobora-se para o estabelecimento de um pensamento teórico-sócio-identitário desde a formação de enfermagem.

Palavras-chave: Globalização, pósmodernidade, cultura pós-moderna, educação em enfermagem, bacharelado em enfermagem, currículo.

\section{RESUMEN}

El objetivo de esta reflexión crítica fue el enfoque de globalización, consumo e identidad, como descripto por Zygmunt Bauman, estableciendo nexos con el trabajo, educación y formación en enfermería. Los resultados y la discusión se segmentaron en tres ejes. El primero contempla cómo la globalización está asociada a la flexibilización del trabajo, la mercantilización de la ciudadanía, los derechos y la salud. El segundo eje refleja dentro del itinerario posmoderno la educación y formación de enfermeros con destaque para los conceptos de educación permanente/política y el papel del profesor. El tercer eje consuma momentáneamente las asertivas, al abordar los obstáculos que la enseñanza globalizada alza como la "formación a distancia". En vano, sería disociar fenómenos globales posmodernos de la coyuntura enfrentada por la profesión. Se corrobora para el establecimiento de un pensamiento teórico-socio-identitario desde la formación de enfermería.

Palabras clave: Globalización, posmodernidad, cultura postmoderna, educación en enfermería, bachillerato en enfermería, currículo.

\section{INTRODUÇÃO}

O primeiro dos modelos de formação e de configuração identitária de enfermagem foi estritamente moralizante e disciplinante, repartindo as atribuições intelectuais para ladies nascidas em melhores camadas sociais e manuais para as menos privilegiadas, as nurses, culminando na enfermeira introduzida em um modelo de eficiência burguês hospitalar. Teóricoadministrativamente o modelo de Taylor e Fayol também serviu para organizar nos ditos capitalistas de produtividade, ainda que na realidade brasileira o "saber e o fazer" bifurquem o trabalho (Geovanini et al., 2002).

No Brasil, o ensino serve-se consideravelmente das bases teóricas da Teoria das Necessidades Humanas Básicas de Wanda Horta e no autocuidado de Dorothea E. Orem, conduzindo assim a Sistematização da Assistência de Enfermagem (SAE) como construção científica e reflexiva privativa do enfermeiro (Oliveira et al., 2016). As questões sociais e seus aprofundamentos e reflexos na formação são relativamente novas, a se considerar os currículos desde a fundação das primeiras escolas de enfermagem como hospitalocêntricos e centrados na cura (Ito et 
al., 2006).

Atemo-nos ao paradigma cultural pósmoderno, que converte a população em clientela de um sistema indeterminado e com poucos compromissos duradouros, onde o $\mathrm{Eu}$ pós-moderno apaga, reescreve e sobrescreve sua identidade e a solidez dos vínculos humanos e conhecimentos dá lugar à paixão pelo descarte. Economicamente e politicamente o mundo experimenta forças díspares e irrefreáveis, pois a soberania econômica, cultural e militar foi abrandada e o cenário mundial povoado por atores que esfacelam do estado-nação poderoso politicamente. A liberdade das finanças, comércio e indústria dependem da extraterritorialidade do capital e da fragmentação. Contrariamente as sociedades passadas a sociedade pós-moderna não precisa de aglomerados de mão de obra, na verdade para continuar crescente e operante necessita de consumidores (Bauman, 1999; Bauman, 2010).

Dado este panorama turbulento, corrobora-se que o definhamento das nações-estados é uma constante que colapsa as relações de poder (Bauman, 1999). Destarte, a enfermagem como ciência moderna frequentemente está coadunada as políticas centrais e imersa com anuência em um mercado de trabalho precário em remuneração e perspectivas além de afetada por políticas hegemônicas (Ito et al., 2006). Nesse sentido, objetiva-se abordar globalização, consumo e identidade (fenômenos descritos no pensamento baumaniano), estabelecendo nexos com trabalho, educação e formação em enfermagem.

\section{METODOLOGIA}

Trata-se de reflexão de teor crítico, dominantemente sobre duas das obras do sociólogo Zygmunt Bauman e suas teorias que versam sobre a crítica a pósmodernidade e ao capitalismo: "Globalização: As Consequências Humanas" (ano de 1999) e "Capitalismo Parasitário" (ano de 2010). Zygmunt Bauman (1925-2017) foi um sociólogo e filósofo polonês reconhecido mundialmente, a alcunha de teórico ou pai da pós-modernidade deve-se a sua extensa reflexão sobre o esgotamento e efemeridade dos vínculos, economia e política, marcando sua postura pessimista e crítica em relação ao capitalismo (Santos, 2014).

Obteve-se a miscelânea a partir de leituras e da técnica do fichamento. Seguidas discussões focalizaram a enfermagem, educação, formação, mercantilização e configuração de identidades com: Globalização, Identidade pós-moderna e Consumo; exigindo um raciocínio indutivo a fim de associar as observações de forma oportuna.

\section{RESULTADOS E DISCUSSÃO \\ A globalização no contexto político e econômico pós-moderno}

Globalização é um conceito moderno que entrecruza o painel mundial com um significado indeterminado, deveras associado ao dinamismo e descentralização de assuntos globais e antagonizando o conceito de universalização, cuja pretensão era expandir o bem-estar e as oportunidades de vida. Os empreendimentos globais derrubaram os intentos do último, inaugurando Estados frágeis nas obrigações sociais e a noção de que não é apenas o mundo que está globalizado, os sujeitos também o estão (Bauman, 1999).

Porém, pondera-se que as metas que intervém nos determinantes sociais de saúde são princípios universalizantes como: 
educação de qualidade, acabar com a fome, reduzir a desigualdade e a pobreza, alcançar a segurança alimentar e nutricional, promover a agricultura, produção e consumo sustentáveis. Em tal caso, há de se pensar em como os ditames globais que engendram cada vez mais desigualdade pretendem de alguma forma fazer o inverso: gerar boas condições de vida e saúde (Labonté, 2016).

Nesta sequência, a pobreza dentro ou fora das grandes cidades é retratada pela mídia por meio de monstruosas imagens de fome, porém a destruição de postos de trabalho nunca é mencionada. Sem o elo causal da mídia parece que os pobres são os responsáveis por suas péssimas condições e a pobreza torna-se a mera falta de alimento, nunca a falta de saúde ou vida digna (Bauman, 1999).

Inter-relacionando estas asseverações, destaca-se a mercantilização da saúde e a dissolução do bem-estar social e da cidadania nas nações capitalistas, onde o estado mínimo e o livre mercado neoliberal acabam por afetar a saúde assegurada pela Constituição de 1988, os indícios são as privatizações e a medicalização sistêmica (Santos, 2013). A única tarefa estatal é a de equilibrar as contas públicas: a economia desune-se da política, a classe dos representantes democraticamente eleitos passa ser cada vez mais supérflua e as megaempresas passam a enxergar o Estado apenas como um coadjuvante, o único poder restante (o repressor) é usado contra os trabalhadores, para deleite dos investidores que fragmentam e escasseiam os empregos. Fundamentam-se os medos vigentes no desemprego, que invariavelmente desloca para os trabalhadores a parte insalubre da globalização. Os ambientes de trabalho são coordenados pelos patrões com o mínimo de energia ou tempo, tudo foi substituído pela exigência de um comportamento ortodoxo dos funcionários, caso contrário, há um contingente de mão de obra esperando pela ocupação do mesmo posto. A autodisciplina é o predicado para a ascensão e as cobiçadas competências técnicas ou da rotina trivializaram-se; as ideias incomuns, inovadoras e a capacidade inventiva são os predicados ambicionados (Bauman, 1999; Bauman, 2010).

Nota-se que consumir serviços e mercadorias, dentro do contexto social brasileiro define a identidade pessoal e a cidadania quando se refere a direitos e deveres, os desníveis de acesso escalonam as pessoas e o direito de consumir contrapõe direitos sociais (Caron et al., 2015). Nesta era o juízo das coisas fugindo ao controle adquiriu precedentes na globalização, pela falta de um centro regulatório e na autopropulsão dos assuntos globais ao bel prazer de gigantes financeiros. $\mathrm{Na}$ flexibilização que tornou os postos de trabalho variáveis economicamente desprovidas de teor social, cujos investidores desvalorizam certos de que a mão de obra sempre será abundante (Bauman, 1999).

Simplificadamente, o diferencial de ênfase é o que marcou a passagem para a sociedade pós-moderna: a antiga era centrada no viver para trabalhar, a atual centrada no consumir para viver (Bauman, 1999). Advém dai os debates da mercantilização da própria cidadania, onde direitos são mercadorias ou alvos de trocas estratégicas (Santos, 2013).

Disparidades observadas na saúde exigem a cercania da compreensão destes fatores históricos, políticos, econômicos e sociais para propiciar intervenções incidentes no status socioeconômico e estilo de vida. Além do mais, os determinantes da saúde são examinados no desenvolvimento de políticas de saúde (Cai et al., 2017). Planos de 
cuidados precisam do enfoque holístico e informações sociais e, infelizmente, existe uma grande lacuna na literatura para enunciar melhores formas desta incorporação (Sullivan et al., 2017).

Outra via de influência da globalização na saúde é a insegurança no trabalho, situação insalubre de habitação e aluguel, níveis mais baixos de renda familiar, subemprego, benefícios inadequados de assistência social e aumento dos custos de vida (Labonté et al., 2015). Uma vez que os políticos conservadores neoliberais perceberam que suas políticas estupefacientes beneficiavam as elites econômicas das quais faziam parte, a dubiedade sobre como o capitalismo pode apoiar a equidade humana e a sustentabilidade, permanecem expostas como um grande mistério (Labonté, 2016).

No âmbito brasileiro o Sistema Único de Saúde é a entidade capaz de ligar a sociedade à esfera da prevenção, cura, tratamento e reabilitação. Nele os mecanismos de participação facultam o engajamento democrático aproximando o povo do Estado (Santos, 2013). Posto isto, se conclamam os enfermeiros em suas responsabilidades sociais na restauração ou busca pela saúde dos usuários, não privilegiando apenas a técnica e sim, compreendendo o ofício como arte na valorização dos programas de saúde (Carvalho, 2011).

\section{Formação e educação diante da mercantilização: apontamentos para a enfermagem}

Por intermédio de associações como a Associação Brasileira de Enfermagem o ideal identitário foi ganhando forma no país, com as políticas de educação e diretrizes curriculares permeando os cursos de graduação (Fonseca, 2017). A prática embasada em evidências cresce dentro dos currículos através de diretrizes conciliando experimentação e exame crítico, respaldando cuidados mediante evidências pesquisadas e revisadas que sejam revertidas em prol de tecnologias de ensino, pesquisa ou assistenciais (Mackey \& Bassendowski, 2017).

Os pilares que guiam a educação podem ser binários (simplificadamente), tanto como meios de massificar e retirar o foco crítico ou meios eficazes de fazer sujeitos assumirem a cidadania (Coelho \& Miranda, 2015). Existe a clara responsabilidade das instituições superiores em transfigurar seus métodos de ensino e aprendizagem em meios de revolucionar a realidade social. Ou seja, a responsabilidade da educação superior em enfermagem no Brasil sempre se correlacionou com o contexto político-social da saúde, habilitando profissionais para a práxis crítica e ajustada aos desígnios contemporâneos (Ito et al., 2006).

Entretanto, as visões fundamentadas em Bauman dão conta que o esquecimento é o parâmetro que dá fluidez ao imediatismo despojado da apreensão de habilidades e fundamentos, pois a cultura vigente é do esquecimento e não da aprendizagem (Bauman, 1999). Transformações sucessivas, instantâneas e voláteis, fazem do homem contemporâneo um baluarte de conhecimentos que em breve serão descartáveis, em uma "economia líquida" que ostenta alto potencial de sedução oriundo do excesso de ofertas, simultaneamente ao rápido potencial de dissipação dos produtos (Bauman, 2010).

Para analisar este paradigma é cabível pensar se os desígnios e vicissitudes do mercado de trabalho, substancialmente hospitalocêntrico, possibilitam que as instituições condigam com um ensino de enfermagem formador (ou potencialmente) de profissionais holísticos, críticos, líderes, 
comunicativos e educadores permanentes (Ito et al., 2006).

Algumas das teorias sobre a escola parecem dar conta de que o caráter emancipatório da educação é utópico devido à exploração e ao escalonamento que as instituições de ensino depreendem (Coelho \& Miranda, 2015). Mudar isto é conjecturar uma educação emancipatória, dando vazão a linhas de raciocínio priorizadoras de debates sociais. Sabe-se que a negociação do trabalho de enfermagem com os grandes hospitais tira do profissional o real valor de seus empreendimentos, logo a continuidade dos cuidados e a força subdividida do trabalho é negociada sem a participação da classe (Brasileiro \& Ribeiro, 2009).

Destarte, no mundo do labor os oprimidos e opressores coexistem e a luta da enfermagem é a luta pela emancipação feminina da submissão ao machismo e ao sistema (Brasileiro \& Ribeiro, 2009). Antes, Florence já escudava a essência dos cuidados em uma autoridade cultivada entre mulheres, em um círculo laboral estritamente feminino, de modo a salvaguardar as enfermeiras do patriarcalismo da medicina (Castro-Molina, 2016).

$\mathrm{Na}$ dinâmica da globalização a enfermagem como legitimada por Madeleine Leininger, é facejada por inúmeros comportamentos e códigos inexplorados. Contudo, a percepção de mundo conferida pela academia tem por obrigação defender uma postura transcultural de humildade e não de julgamentos cientificistas (Rosa, 2017). Conservar uma relação empática é um dos cernes da Teoria do Cuidado Humano de Jean Watson, as informações proferidas pelos usuários devem ser escutadas por um profissional holístico e não apenas afigurado como um executor de procedimentos técnicos (Savieto \& Leão, 2016).

Outrossim, uma educação permanente deve ser discutida em vistas de outras racionalidades, não abandonando totalmente o modo tradicional, mas sim adicioná-lo a um contexto mais abrangente $\mathrm{e}$ contemporâneo (Koerich \& Erdmann, 2016). A congruência existente entre educação permanente e educação continuada é a busca perdurável por novos saberes, novas técnicas e valores (políticos e sociais) (Sousa et al., 2015).

A educação permanente assimila-se ao cotidiano e suas significações muitas vezes confundem-se com educação continuada (Sousa et al., 2015; Koerich \& Erdmann, 2016). Confundir os conceitos denota a predisposição do enfermeiro em encarar como atividades pedagógicas quaisquer atualizações, pois extensivamente a educação permanente alicerça-se sobre situações cotidianas (Sousa et al., 2015). Acercar-se permite compreender e contextualizar a prática, tratando-a como uma troca de saberes dialógica, política, gerencial e comunicativa, projetadas nos cuidados (Koerich \& Erdmann, 2016). Bauman (2010) crê que a obsessão pela educação permanente se deva ao binômio da constante atualização da informação e da crença, irônica, de que a personalidade é uma fonte inesgotável.

Sabe-se que a pedagogia tradicional é usada em demasia pelos docentes, porém mais contemporaneamente, metodologias críticas passam a estabelecer a interface sociocultural partindo dos aspectos subjetivos dos homens (Coelho \& Miranda, 2015). Outrora o professor conduz estudantes nos campos de prática, contribuindo para o afloramento da comunicação e expressão dos discentes (Oliveira \& Braga, 2016). 
Dada a importância do professor e os conflitos decorrentes das possibilidades de reforma da pedagogia na globalização, acentuam-se aqui que parte dos desafios nas relações professor-aluno são análogos à incompreensão. A "desconfiança intergeracional" é o choque entre gerações, a incredulidade dos tradicionalistas vai de encontro à vontade dos jovens de mudarem o mundo. Geralmente uns estão presos aos padrões imutáveis de normalidade e conservação, enquanto os outros se sentem impelidos à moção de reformar (Bauman, 2010).

\section{Impasses do ensino globalizado: especial caso da "formação à distância"}

A essência identitária da profissão encontra-se historicamente ligada ao fazer feminino invisível, no reestabelecimento das competências físicas e psicológicas para o autocuidado melhorado ou na adaptação dos pacientes. Delimitar tal identidade no Brasil foi um esforço de enfermeiras pioneiras, ao idearem a Associação Brasileira de Enfermagem (tripé social) e a primeira revista de publicações científicas (tripé teórico) (Oguisso \& Freitas, 2016).

Tracejam-se padrões assistenciais holísticos com o primor pelos dotes técnicos e relacionais, o prosseguimento dos estudos em programas de pós-graduação e métodos de ensino novos (Savieto \& Leão, 2016). Sem embargo, mais inovações serão possíveis por intermédio de mais pesquisas e reflexões aspirando à emancipação da mulher e da saúde brasileira (Brasileiro \& Ribeiro, 2009). Para abordar o foco educacional, duas questões geradoras de impasses na formação devem sofrer rápida arguição: 1) os conceitos de prática e teoria comumente separados e 2) ensino versus consumo.

Primeiramente, pensa-se na abordagem conceitual de teoria contida nos currículos e na prática e práxis. A prática mecanicista em uma análise didática ilustra-se enquanto ações não totalmente conscientes - da totalidade da qual participam, perfazendo uma trajetória sem avaliações e teorizações, não permitindo a expansão para a práxis perfeitamente contextualizada. A teoria quando focalizada separadamente da prática, dissimula os aspectos pragmáticos, ou seja, incide na contemplação, idealização e abstracionismo (Pereira, 2003).

Balizar a criticidade na superação desta díade é dar vazão a contrapontos desta visão enraizada no seio profissional, na qual a assistência tem maior congruência com a prática e a teorização maior afinidade com a pesquisa e docência, quando na verdade a práxis está contida em ambas. Porém, não é exclusivamente deste antigo impasse educacional que a profissão está absorta, o compromisso político ou a falta dele é outro empecilho.

A formação de enfermeiros vem mudando perante o vislumbre das ferramentas digitais e multimídia, aguçando o convívio e a dialogia, principalmente entre os pesquisadores. Conquanto, a enfermagem nacional defronta-se com obstáculos para seus intentos organizacionais e políticos, de valorização da vida, saúde e coletividade. Estes obstáculos são o individualismo e antagonização dentro da própria classe (Fonseca, 2017).

Precedentemente, evidenciaram-se transformações sociais ligadas à avidez por buscar, fortuitamente não encontrar e consumir para manter o status quo: o consumidor como o homem em movimento (Bauman, 1999). Não obstante, se começa a validar a afirmação que indivíduo pósmoderno é consumidor do ensino; argumentam-se entraves educacionais na globalização: o convencimento de que a educação é um bem vital em virtude das 
facilidades do mundo, à proporção que a aleatoriedade das transformações vividas embotam as possibilidades de representar fidedignamente a realidade, na qual o saber existente sempre será questionado e (re)atualizado. Outra é que os discentes pósmodernos cobram a aquisição de um "conhecimento operativo" sem espaço para extensivas teorizações, procuram consultores e coachings para ensinar a caminhar facilmente pela academia apontando onde residem informações certas e quais carecem de maior atenção. A crise questiona os constituintes da educação, sua missão e seus resultados na melhoria do mundo, geralmente são os jovens que assumem este protagonismo argumentativo (Bauman, 2010).

Manter-se instigado perduravelmente é desafiador quando a moda do consumo leva sujeitos a serem impacientes e sempre seduzidos por tentações (Bauman, 1999). Um nítido exemplo das tentações do "ensino globalizado" é o ensino de enfermagem à distância $(\mathrm{EaD})$. Fez-se necessário projeto de lei apoiado em parecer do Conselho Federal de Enfermagem, para opor-se e sinalizar o obviamente claro: os cursos de $\mathrm{EaD}$ não abarcam a realidade da profissão do cuidar humano (Projeto de Lei 2891, 2015), não como preconizado pela empatia de Jean Watson tampouco pela transculturalidade de Madeleine Leininger.

\section{Como a moda da formação EaD colabora com o consumismo pós- moderno?}

Enxerga-se na internet a capacidade interativa e a possibilidade de apagar, reescrever e sobrescrever as identidades, desta reidentificação advém a descartabilidade e o gozo do consumismo. $\mathrm{O}$ compromisso social das universidades deve ser suscitado diante:
No turbilhão de mudanças, é muito mais atraente o conhecimento criado para usar e jogar fora, o conhecimento pronto para utilização e eliminação instantâneas, o tipo de conhecimento prometido pelos programas de computador que entram e saem das prateleiras [...] (Bauman, 2010, p. $42)$.

Segundo o autor o conceito de educação passou a ser vacilante em meio às armadilhas do esquecimento, e o aprendizado está fadado a perseguir ideais móveis que tão $\log$ o são aprendidos pelo aluno, dissipam-se (Bauman, 2010). Aqui não se fala na eficácia das ferramentas digitais ou semipresenciais no ensino de enfermagem, mas sim de como a educação torna-se um produto cooptado, rechaçando a educação institucional (Bauman, 1999), através da redução do tempo e da alta oferta de cursos EaD.

Por outro lado, a mídia permeia os espaços assessorando o consumo, e a televisão é o meio de comunicação que dita o modelo de saúde. Aparentemente o hospital é o único recinto onde existem equipamentos e trabalhadores capazes de frear doenças e a morte, o mote disto é um "hospitalocentrismo" estimulado pelo ideal consumista (Caron et al., 2015).

Interpelar pelo comprometimento político é um meio verossímil para a luta, mesmo assim, a participação em movimentos sociais é irrisória e as pautas políticas são relegadas ao segundo plano em congressos. $\mathrm{O}$ expediente da enfermagem é árduo, finda por não permitir que a totalidade de enfermeiros empenhem-se em pesquisas e na revolução (Brasileiro \& Ribeiro, 2009). O apoio institucional comedido ergue barreiras inclusive para o empenho na educação permanente (Koerich \& Erdmann, 2016).

Heuristicamente, o tripé político é necessário para a efetivação destes anseios, 
apesar disto sabe-se que apenas um número mitigado de enfermeiros usufrui de cargos políticos (Brasileiro \& Ribeiro, 2009). Chegar neste patamar tão caótico e fluido é assustador. Confrontar-se com a sensação de que a totalidade dos logos construídos e apreendidos até hoje acumularam-se, produzindo uma sociedade pouco ortodoxa, sem ideais de pertinência e determinantes de valor humano. A ameaça à autoconfiança vem do fato de admirar esta massa de informações e crer que nela estão decifrados os problemas sociais (Bauman, 2010).

\section{CONSIDERAÇÕES CONTRIBUTOS \\ FINAIS E ENFERMAGEM}

Nesta reflexão avaliamos que a globalização ou globalizar-se são fenômenos mundiais que inegavelmente vociferam a formulação de um currículo político, amiúde, o docente dispõe de um papel primordial: fomentar novas epistemologias através teorias de enfermagem que dão substratos valiosos - por guarnecerem a educação humanisticamente, e encarar a da educação permanente como composição de formação política e não apenas capacitação e reciclagem técnica. É indiscutível o novo papel do docente de enfermagem como catalisador de conhecimentos e atualidades, moderador e instigador político.

Em suma, acredita-se desde a gênese desta reflexão que o maior contributo para formação e educação ante a globalização e o consumismo na pós-modernidade é a fixação do pensamento teórico-sócioidentitário da enfermagem, desde a formação acadêmica. Teórico enquanto aliase aos pressupostos teóricos e práticos (práxis) e valoriza o mundo dos saberes; Social ao valorizar a história da profissão e comprometer-se com os ideais juramentados à população (universalidade, equidade e integralidade) e Identitário por se relacionar dinamicamente com os membros da profissão em um fazer conjunto pela construção de espaços de valorização do enfermeiro.

\section{REFERÊNCIAS}

- Bauman, Z. (1999). Globalização: as consequências humanas. Rio de Janeiro: Zahar.

- Bauman, Z. (2010). Capitalismo parasitário: e outros temas contemporâneos. Rio de Janeiro: Zahar.

- Brasileiro, M. S. E., Ribeiro, Z. F. (2009). Mulher, Enfermagem, Saúde e Religião: reflexões sobre a luta pela emancipação. Revista Eletrônica de Enfermagem do Centro de Estudos de Enfermagem $e$ Nutrição [serial on-line], 1(1), 1-16.

- Cai, J., Coyte, P. C. \& Zhao, H. (2017). Determinants of and socio-economic disparities in self-rated health in China. International Journal for Equity in Health, 16(1), 7.

- Caron, E., Lefèvre, F. \& Lefèvre, A. M. C. (2015). In the final analysis, are we a consumer society or not? Implications for health. Ciência \& Saúde Coletiva, 20(1), 145-153.

- Carvalho, V. D. (2011). Ethics and values in health care practice: philosophical, educational, and political considerations. Revista da Escola de Enfermagem da USP, 45(SPE2), 1797-1802.

- Castro-Molina, F.J. (2016). La enfermera victoriana: género e imperio. Cultura de los Cuidados (Edición digital), 20(46).

- Coelho, M. D. M. F. \& Miranda, K. C. L. (2015). Educação para emancipação dos sujeitos: reflexões sobre a prática educativa de enfermeiros. Revista de Enfermagem do Centro-Oeste Mineiro, 5(2), 1714-1721.

- Fonseca, R. M. G. S. (2017). Enfrentando desafios em tempos de adversidades. Revista Brasileira de Enfermagem, 70(1), 1-2.

- Geovanini, T., Dornelles, S., Moreira, A., Machado, W. C. A. (2002). A Enfermagem Moderna. Em História da Enfermagem: versões e interpretações (pp. 291-299). Rio de Janeiro: Revinter.

- Ito, E. E., Peres, A. M., Takahashi, R. T. \& Leite, M. M. J. (2006). O ensino de enfermagem e as diretrizes curriculares nacionais: utopia x realidade. Revista da Escola de Enfermagem da USP, 40(4), 570-575.

- Koerich, C. \& Erdmann, A. L. (2016). Significados atribuídos pela equipe de enfermagem sobre educação permanente em uma instituição 
cardiovascular. Northeast Network Nursing Journal, 17(1), 93-102.

- Labonté, R. (2016). Health promotion in an age of normative equity and rampant inequality. International Journal of Health Policy and Management, 5(12), 675.

- Labonté, R., Cobbett, E., Orsini, M., Spitzer, D., Schrecker, T. \& Ruckert, A. (2015). Globalization and the health of Canadians: 'Having a job is the most important thing'. Globalization and health, 11(1), 19.

- Mackey, A. \& Bassendowski, S. (2017). The History of Evidence-Based Practice in Nursing Education and Practice. Journal of Professional Nursing, 33(1), 51-55.

- Oguisso, T. \& de Freitas, G. F. (2016). Cuidadoessência da identidade profissional de Enfermagem. Revista da Escola de Enfermagem da USP, 50(2), 188-189.

- Oliveira, K. R. E. D. \& Braga, E. M. (2016). The development of communication skills and the teacher's performance in the nursing student's perspective. Revista da Escola de Enfermagem da USP, 50(SPE), 32-38.

- Oliveira, R. S., da Cruz Almeida, E., de Azevedo, N. M., de Almeida, M. A. P. \& de Oliveira, J. G. C. (2016). Reflexões sobre as bases científicas e fundamentação legal para aplicação da Sistematização do Cuidado de Enfermagem. Revista Uniabeu, 8(20), 350-362.

- Pereira, O. (2003). O que é teoria. São Paulo: Brasiliense.

- Projeto de Lei 2891 de 2015. Altera a Lei n. ${ }^{\circ}$ 7.498, de 25 de junho de 1986, que regulamenta o exercício da enfermagem, para nela incluir a obrigatoriedade de formação exclusivamente em cursos presenciais para os profissionais da área. Recuperado de http://www.camara.gov.br/proposicoesWeb/prop $\underline{\text { mostrarintegra? codteor }=1381160 \text { \&filename }=\mathrm{PL}+28}$ 91/2015.

- Rosa, W. (2017). Immersing in Context: A Requisite for Socially Responsible Transcultural Nursing. Journal of Transcultural Nursing, 28(2), 117-118.

- Santos, D. M. B. (2014). ZYGMUNT BAUMAN: Vida, obra e influências autorais. Cadernos Zygmunt Bauman, 4(8), 83-113.

- Santos, P. L. P. (2013). Mercantilização da saúde e cidadania perdida: o papel do sus na reafirmação da saúde como direito social. Revista da UNIFEBE, $1(11)$.

- Savieto, R. M. \& Leão, E. R. (2016). Nursing assistance and Jean Watson: a reflection on empathy. Escola Anna Nery, 20(1), 198-202.

- Sousa, M. D. S. T., Brandão, I. R. \& Parente, J. R. F. (2015). A percepção dos enfermeiros sobre Educação Permanente em Saúde no contexto da Estratégia Saúde da Família de Sobral (CE). Revista Interfaces: Saúde, Humanas e Tecnologia, 3(1). Recuperado de http://interfaces.leaosampaio.edu.br/index.php/re vista-interfaces/article/view/260/155.

- Sullivan, S. S., Mistretta, F., Casucci, S. \& Hewner, S. (2017). Integrating social context into comprehensive shared care plans: A scoping review. Nursing Outlook, 1-10. 